\title{
Neurophysiological assessment of alpha pattern coma
}

\author{
J A OBESO, MI IRAGUi, JF MARTI-MASSO, E MARAVI, JM TEIJEIRA, \\ N CARRERA, AND J TEIJEIRA
}

From the division of Neurology, Residencia Sanitaria, San Sebastian, and the Department of Clinical Neurophysiology and division of Neurology, Residencia Sanitaria, Pamplona, Spain

S U M M A R Y Somatosensory evoked potentials, blink reflexes, and $\mathrm{H}$ wave reflexes, were recorded on several days from three patients with alph pattern coma. Coma was secondary to cardiac arrest in two cases and to brainstem infarction in one. Results are compatible with damage to the brainstem reticular formation with sparing of thalamo-cortical circuits as the main physiopathological characteristic of alpha pattern coma. This condition should not be regarded as a discrete entity when establishing the prognosis of patients in coma, since they only differ from other patients in coma from the point view of the EEG record.

Comatose patients whose electroencephalographic activity is predominantly of alpha frequency have been the subject of several reports over the last few years. Early publications correlated brainstem lesions, particularly in the pons, with the appearance of this type of EEG tracing, ${ }^{1-4}$ and only recently have there been reports of alpha pattern coma in patients after cardiopulmonary arrest. $^{5-7}$ The general opinion is that alpha pattern coma has an extremely bad prognosis, but recent evidence indicates that the chance of survival is no lower in comatose patients with EEG rhythm of alpha frequency than in those in coma associated with slow EEG waves. ${ }^{8}$

Whether the alpha pattern represents a pathological rhythm or retained normal activity has not been elucidated. In the present paper we describe a detailed electrophysiological study of three patients with alpha pattern coma, and the neuropathological data from one of them.

\section{Case reports}

CASE 1

A 72 year old woman was admitted to hospital because she was dysarthric and complained of unsteady gait. By the time she reached hospital she was in coma and her pupils were myotic but reactive to light. Horizontal oculocephalic move-

Address for reprint requests: Dr JA Abeso, Augusto Linares 4, Torrelavega, Santander, Spain.

Accepted 27 June 1979 ments were normally present, but vertical movements could not be elicited. Corneal reflexes were present bilaterally. Her extremities were diffusely rigid, and plantar responses were extensor. Five days later the patient showed spontaneous decerebrate motor posture on both sides of her body. Oculocephalic and oculovestibular reflexes were no longer present; breathing was spontaneous. On the thirteenth day in hospital her temperature rose to $41^{\circ} \mathrm{C}$, with a respiratory infection. Breathing became irregular and mechanical respiration was needed. Three days later she died. The brain necropsy revealed thrombosis of the basilar artery with infarction involving the entire rostral two-thirds of the basis pontis bilaterally, with scattered ischaemic lesions in the tegmentum (fig 1). The infarct also involved both sides of the cerebellum.

\section{CASE 2}

A 55 year old man had a sustained period of cardiac arrest during a traffic accident, after which he remained unconscious. On admission, pupils were in mid position and reactive to light. His extremities were diffusely rigid, and a right extensor plantar response was noted. Corneal reflexes were depressed but present on both sides. Oculocephalic movements were normal; breathing was regular. Two days later, a right lobar pneumonia became an important hazard, and the patient died four days after the cardiac arrest. Data from necropsy could not be obtained. 


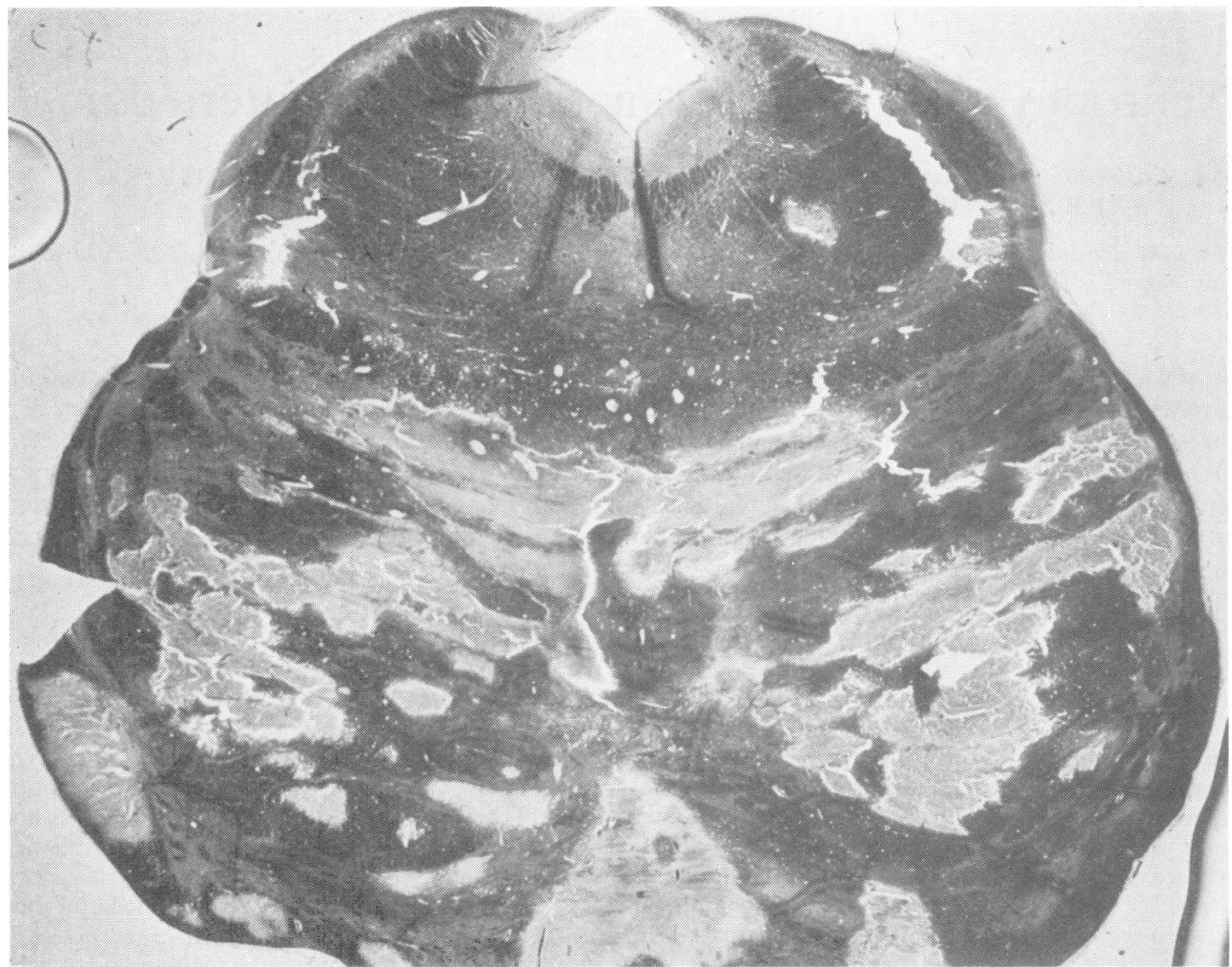

Fig. 1 Myelin sheath stain of a transverse section through the rostral part of the pons in case 1. Extensive infarction of the basis pontis is observed, with scattered lesions appearing on the tegmentum.

\section{CASE 3}

This 48 year old man suffered a cardiac infarction and secondary cardiac arrest while coming to the hospital. On admission he was in coma, pupils were myotic, oculocephalic and corneal reflexes were normal bilaterally, and lower limbs were slightly hypotonic but tendon jerk reflexes could be elicited easily. An extensor plantar response was noted on the right. Breathing was normal. The ECG showed signs of acute anterior myocardial infarction. On the following days the pupils were clearly reactive to light, but no other sign of recovery was observed. Eight days after admission, he had a new and irreversible cardiac arrest. Necropsy was not performed.

\section{Neurophysiological procedure}

The EEG was recorded with an eight channel portable aapparatus. Spin electrodes of $7 \mathrm{~mm}$ diameter were used for recording of both the EEG and somatosensory evoked potentials (SEPs). They were placed according to the 10-20 system. ${ }^{\ominus}$ All patients were stimulated by hand claps, light flashes, and pinching of the extremities. Electroencephalograms were recorded every two or three days, thus case 1 had eight tracing at daily intervals. Case 2 had only three recordings, and case 3 had five EEGs. Somatosensory evoked potentials were elicited by median nerve stimulation at the wrist, using a stimulus amplitude of $10 \%$ above the motor threshold for the opponens pollicis muscle. The stimulation rate was 0.5 per second. The active electrode was placed $20 \mathrm{~mm}$ behind $\mathrm{C} 3$ and $\mathrm{C} 4$, while the reference electrode was on the midfrontal region $\left(F_{z}\right)$. One set of tests consisted of 256 responses, repeated two or three times. Analysis time was $200 \mathrm{~ms}$, and the amplifiers had a flat frequency response from 2 to $1000 \mathrm{~Hz}$ and a high frequency 
roll-off at $24 \mathrm{~dB} /$ octave above $1500 \mathrm{~Hz}$. Latencies were measured from the stimulus to each peak, and the amplitude was defined as the height of successive positive-negative peaks. Somatosensory evoked potentials were recorded at least three times on different days. The blink reflex was obtained by supraorbital nerve stimulation over the supraorbital foramen, and the muscular responses were recorded from the orbicularis oculi muscle on both sides simultaneously. $\mathrm{H}_{\max }$ and $\mathbf{M}_{\max }$ waves were recorded over both soleus muscles after stimulation at the popliteal fossa as recommended by Hugon. ${ }^{10}$ Each potential repre!ents the average of 10 responses.

\section{Results}

\section{ELECTROENCEPHALOGRAPHY}

The dominant EEG activity was within the alpha frequency at the first recording in the three patients. However none had reactivity to external stimulation, and alpha waves were diffused over frontal regions. Cases 1 and 3 deteriorated rather slowly and their EEG became progressively abnormal on the days after admission. The evolution of case 2 was very fast, and his EEG changed from alpha frequency to being isoelectric.

\section{SOMATOSENSORY EVOKED POTENTIALS}

Mean values for SEP parameters over both hemispheres are shown in table 1 . The SEPs of case 1 were nearly normal on the first day, becoming progressively simplified in later recordings, along with EEG deterioration (figs 2, 3, and 4). High amplitude of N3 and N4 waves on the first days, and later attenuation of these waves were the most constant findings. A monophasic positive wave (fig 4) was eventually the only recordable response. No SEP could be evoked in any case with an isoelectric EEG tracing.

Table 1 Somatosensory evoked potentials: mean values and $H / M$ amplitude coefficient in three patients with alpha coma

\begin{tabular}{llllll}
\hline & & \multicolumn{3}{c}{$S E P s^{*}$} & \multicolumn{2}{c}{$H / M^{*}$} \\
& & $N 1$ & $N 2$ & $N 3$ & $\%$ \\
\hline Case 1 & Amplitude $(\mu \mathrm{V})$ & 5.0 & 4.5 & $14^{* *}$ & $68^{* *}$ \\
& Latency $(\mathrm{ms})$ & 21 & 33 & 72 & \\
Case 2 & Amplitude $(\mu \mathrm{V})$ & 4.6 & 4.8 & Absent & $59^{* *}$ \\
& Latency $(\mathrm{ms})$ & 20.5 & 31 & & \\
Case 3 & Amplitude $(\mu \mathrm{V})$ & 5.3 & 4.9 & Absent & $62^{* *}$ \\
& Latency $(\mathrm{ms})$ & 22.8 & 32 & & \\
& & & & & \\
\hline
\end{tabular}

*Average of both sides.

**More than 2.38 standard deviations from normal.

\section{BLINK REFLEX}

The $\mathrm{R} 1$ blink responses were normal bilaterally in the three cases, but $R 2$ responses were delayed on both sides in cases 2 and 3, while the late response was absent bilaterally in case 1 (table 2 ).

Table 2 Mean latencies of $R 1$ and $R 2$ components of the blink reflex in three patients with alpha coma (46 responses considering both sides together)

\begin{tabular}{llllll}
\hline Case & $R 1$ & $\begin{array}{l}\text { Difference } \\
\text { between } \\
\text { sides }\end{array}$ & D.rect R2 & Consensual R2 & $\begin{array}{l}\text { Difference } \\
\text { between } \\
\text { sides }\end{array}$ \\
1 & $(m s)$ & $(m s)$ & $(m s)$ & $(m s)$ & $(m s)$ \\
2 & 10.3 & 0.38 & Absent & Absent & $\frac{2.12}{2.7}$ \\
3 & 11.5 & 0.41 & $46.2^{*}$ & $48.8^{*}$ & 2.08 \\
\hline
\end{tabular}

* More than 2.38 standard deviations from normal.

H REFLEX

The $H / M$ amplitude ratio was pathologically increased in all three patients (table 1), with case 1 showing the most remarkable increment.

\section{Discussion}

It seems well established ${ }^{146}$ that the neuronal population responsible for generating a wakeful type of alpha pattern lies rostral to the pontomesencephalic junction. Experimental data suggest that generation of alpha rhythm depends on thalamocortical circuits, ${ }^{11}$ while EEG desynchronisation is not possible when the nucleus reticularis pontis oralis has been destroyed. ${ }^{12}$

In our three patients, SEPs had an evolution similar to those recorded from patients in coma without alpha pattern. ${ }^{13}{ }^{14}$ Most reports on evoked potentials during coma agree in showing relatively normal short latency potentials and abnormal or absent long latency waves at the early stages of coma. ${ }^{131516}$ High amplitude of SEP late waves are seen in patients with brainstem lesions, ${ }^{17}{ }^{18}$ which seems related to damage of the brainstem reticular formation. ${ }^{19} 20$ On the other hand high $\mathrm{H} / \mathrm{M}$ ratios occur after removal of supraspinal inhibition by a lesion of the reticulospinal pathways, ${ }^{21}$ et al and the late blink reflex response (R2) is absent when the pontomedullary reticular formation is sectioned. ${ }^{22}$

For these reasons we think that alpha pattern coma occurs from damage of the brainstem reticular formation with sufficient sparing of the diencephalic and cortical neurones to generate an alpha rhythm. Our three patients with alpha coma did not differ from a neurophysiological point of view from other patients in coma, and cortical responses may be present in patients with 

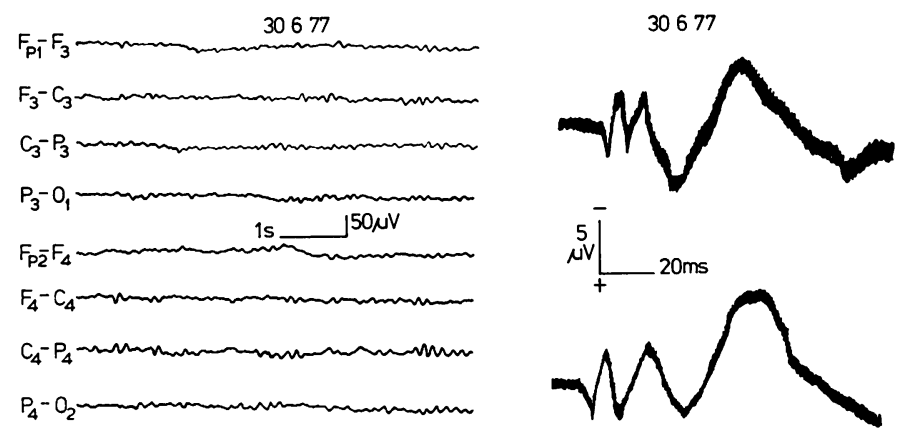

Fig 2 EEG and SEPs of case 1 two days after admission. Alpha rhythm and SEPs of normal latencies and high amplitude of $N 3$ wave were recorded.
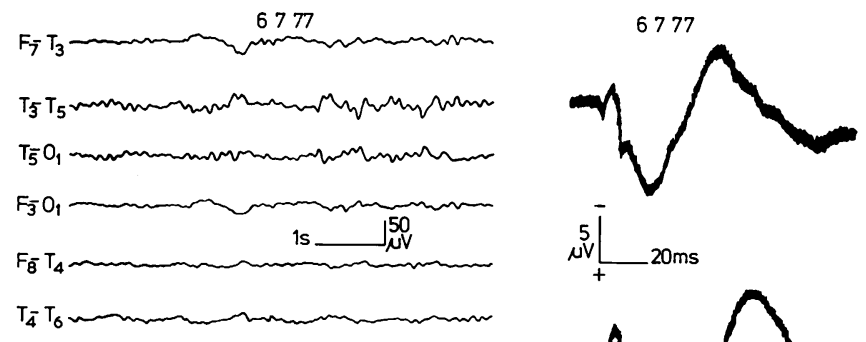

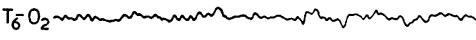
$\mathrm{F}_{2} \mathrm{O}_{2}$

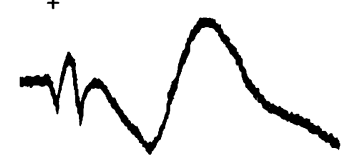

Fig 3 The same record on case 1 on the sixth hospital day. The EEG is slower and SEPs have lost their late waves.

14777

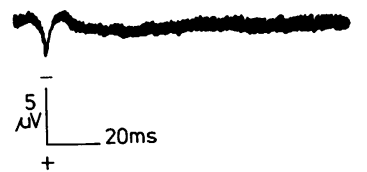

Fig 4 Marked EEG slowing along with a simple positive wave in both SEPs at the final stage of life in case 1.

alpha coma when the afferent pathways are spared, as in case 1 (fig 1). The failure of the EEG to desynchronise in most reported cases may be related to a lesion of the nucleus reticularis pontis oralis, but further neuropathological data from patients with alpha coma of metabolic origin are needed to establish such a correlation. Alpha coma does not invariably portend a poor prognosis, and indeed the chance of survival or residual disability is the same as in other individuals in coma. $^{8}$ Thus alpha coma should be only considered as a dissociation between consciousness and the EEG, because both phenomena are partially independent. Detailed neurophysiological studies along with clinical data may be useful in the evolution of patients with alpha pattern coma, overcoming the absolute limitation of EEG recording.

We would like to thank Mrs M Martin for technical assistance. 


\section{References}

1 Loeb C, Poggio G. Electroencephalograms in a case with ponto-mesencephalic hemorrhage. Electroencephalogr Clin Neurophysiol 1953; 5: 295-6.

2 Lundervold A, Hauge T, Loken AC. Unusual EEG in unconscious patients with brainstem atrophy. Electroencephal Clin Neurophysiol 1956; 8:665-70.

3 Chatrian GE, White LE, Shaw CM. EEG pattern resmbling wakefulness in unresponsive decerebrate state following traumatic brainstem infarct. Electroencephalog Clin Neurophysiol 1964; 16:285-9.

4 Wilkus RJ, Harvey F, Ojemann LM. EEG and sensory evoked potentials. Findings in an unresponsive patient with pontine infarction. Arch Neurol 1971; 24:538-44.

5 Vignaedra V, Wilkus RJ, Copass MK, Chatrian GE. Electroencephalographic rhythms of alpha frequency in comatose patients after cardiopulmonary arrest. Neurology (Minneap) 1974; 24:582-8.

6 Westmoreland BF, Klass DW, Sharbrough FW, Reagan TJ. "Alpha coma". Electroencephalographic, clinical, pathological and etiologic correlations. Arch Neurol 1975; 32:713-8.

7 Chokroverty S. "Alpha-like" rhythms in electroencephalograms in coma after cardiac arrest. Neurology (Minneap) 1975; 25:655-63.

8 Sorensen K, Thomassen A, Wernberg M. Prognostic significance of alpha frequency EEG rhythm in coma after cardiac arrest. $J$ Neurol Neurosurg Psychiatry 1978; 41:840-2.

9 Jasper HH. The ten-twenty electrodes system of the International Federation. Electroencephalogr Clin Neurophysiol 1958; 10:371-5.

10 Hugon M. Methodology of the Hoffmann reflex in man. In: Desmedt JE, ed. New Developments in Electromyography and Clinical Neurophysiology, vol 3. Basel: Karger, 1973; 277-93.

11 Andersen P, Andersson SA. Thalamic origin of cortical rhythmic activity. In: Rémond A, ed. Handbook of Electroencephalography and Clinical Neurophysiology, vol 2. Amsterdam: Elsevier, 1974; 90-118.

12 Camacho-Evangelista A, Reinoso-Suarez F.
Activating and synchronizing centers in cat brain: electroencephalograms after lesions. Science 1964; 146:268-70.

13 Greenberg RP, Becker P, Miller JD, Mayer DJ. Evaluation of brain function in severe human head trauma with multimodality evoked potentials. Part 2. Localization of brain dysfunction and correlation with posttraumatic neurological conditions. J Neurosurg 1977; 47:163-77.

14 Obeso JA, Teijeira JM, Marti-Masso JF et al. Somatosensory evoked potentials: abnormalities in brainstem lesions. Electromyogr Clin Neurophysiology 1979; in press.

15 Arfel G. Stimulations visuelles et silence cerebral. Electroencephalogr Clin Neurophysiol 1967; 23:172-5.

16 Trojaborg W, Jorgensen EO. Evoked cortical potentials in patients with "isoelectric" EEGs. Electroencephalogr Clin Neurophysiol 1973; 35: 301-9.

17 Halliday AM. Changes in the form of cerebral evoked responses in man associated with various lesions of the nervous system. Electroencephalogr Clin Neurophysiol 1967; Suppl 25: 178-92.

18 Obeso JA, Marti-Masso JF, Iragui MI, Teijeira JM, Carrera N, Teijeira J. Valor de los potenciales evocados somatosensoriales en la evaluación funcional de pacientes en coma. Med Clin (Barcelona) 1979; in press.

19 Reinoso-Suarez F. Effects of diencephalic and mesencephalic lesions upon afferent impulses in the central sensory pathways. Electroencephalogr Clin Neurophysiol 1963; suppl 24: 33-42.

20 Cantor FK, Ilborg F. Facilitation of photic responses by focal lesions. Electroencephalogr Clin Neurophysiol 1973; 36:214-25.

21 Pierrot E, Bussel B, Morin C. Supra-spinal control of the changes induced in H-reflex by cutaneous stimulation, as studied in normal and spastic men. In: Desmedt JE, ed. New Developments in Electromyography and Clinical Neurophysiology, vol 3. Basel: Karger, 1973; 550-55.

22 Ongerboer de Visser BW, Kuypers HGJM. Late blink reflex changes in lateral medullary lesions. Brain 1978; 101:285-94. 